\title{
La ordenanza de bienes culturales como instrumento para la protección del patrimonio urbano-arquitectónico
}

Rebeca Medina *

\section{Resumen}

Los Estados Partes que poseen bienes reconocidos por la UNESCO como Patrimonio de la Humanidad deben garantizar según el Art.5, inc. d, la adopción de "medidas jurídicas (...) para identificar, proteger, conservar, revalorizar y rehabilitar el patrimonio".

Un estudio de las ordenanzas para la protección de bienes culturales vigentes en Argentina, y su comparación con normas similares, evidencian carencias en su formulación, entre las que pueden mencionar:

1. ¿Qué se protege? ¿Dónde se protege? La identificación del bien y las consideraciones jurídicas sobre su entorno.

2. ¿Quién protege al bien inmueble: el municipio, la provincia, la nación? ¿Mediante que organismos lo hace: cultura-urbanismo? La Autoridad de Aplicación.

3. ¿Cómo asegurar la protección del bien inmueble? Los incentivos a la protección de los bienes culturales arquitectónicos.

El artículo desarrolla la propuesta y fundamentación de una estructura tipo para la elaboración de ordenanzas relacionadas con el reconocimiento y protección del patrimonio urbano-arquitectónico en el nivel municipal, instrumento jurídico base para cumplir con la obligación citada.

Palabras Claves: Derecho. Patrimonio Cultural. Ordenanzas Municipales. Recomendaciones

Title: Preservation guidelines as an instrument for the protection of urbanarchitectural heritage

\footnotetext{
Abstract

According to Article 5 of UNESCO's Convention Concerning the Protection of the World Cultural and Natural Heritage, each State Party should "take the appropriate legal (...) measures necessary for the identification, protection, conservation, presentation and rehabilitation of the world's heritage".
} 
An evaluation of Argentinean preservation guidelines, and their comparison with similar ones, evidence certain wants in their formulation, among which can be mentioned: 1. What assets are to be preserved? Where are they located? The identification of cultural heritage and the legal considerations about their immediate environment.

2. Whose responsibility is it: city, state or federal authorities? Are the institutions directly involved of a cultural or urban nature? The authority of enforcement.

3. How to secure the protection of landmarks? Available incentives respecting their protection.

The present paper presents a justified proposition for a legal frame concerning the elaboration of guidelines for the recognition and protection of urban-architectural heritage at city level, considered to be the basic legal tool in order to achieve the above mentioned commitment.

Key words: Law. Cultural Heritage. Municipal Guidelines. Recommendations.

\section{Introducción}

El problema de la desaparición del patrimonio cultural no es solo de preocupación, sino de ocupación, para lo cual el qué y el quién es de definición imprescindible, el cómo un programa resultado del diagnóstico, el cuánto un trabajo de identificación, el dónde el espacio definido en el programa, y el cuándo el momento político oportuno.

El Municipio es el nivel administrativo que está en diario contacto con los bienes culturales arquitectónicos y urbanos. A él le corresponde en la República Argentina el reconocimiento y la protección de mismo, ya que, por ejemplo, de acuerdo a la Constitución de la Provincia de Córdoba, es de su competencia - Art. 186.8 - el "conservar y defender el patrimonio histórico y artístico, disponer y fomentar política de apoyo a los valores culturales".

Para cumplir con esa misión el municipio argentino cuenta con múltiples atribuciones: planes edilicios, diseño y estética, planes urbanísticos, protección del medio ambiente y el paisaje, etc. Algunas de sus atribuciones son muy explícitas y en otros casos más ambiguas a la hora de delimitar las competencias. 
Además, algunas Cartas Orgánica Municipales reiteran estas incumbencias. Por ejemplo, según el Art.12 de la Carta Orgánica de la Ciudad de Córdoba, el Municipio tiene el deber de "conservar y proteger los intereses y el Patrimonio Histórico Cultural de la Ciudad" y de "proyectar, concertar y ejecutar acciones de renovación y preservación de áreas y componentes del patrimonio histórico, urbano arquitectónico, arqueológico y paisajístico de la ciudad" de acuerdo al Art. 27.2. Es decir de redactar para los bienes culturales arquitectónicos normas urbanas que cumplan con dichas exigencias.

La consideración del urbanismo como función pública permite la redacción de ordenanzas especiales por el reconocido valor social de la propiedad. Siendo la ciudad un hecho colectivo, los poderes públicos tienen la facultad de definir el estatuto que alcanza al propietario del suelo y, entonces, el derecho a edificar ó a modificar una edificación es entendido como un derecho desligado de la propiedad del suelo, al que sólo se llega tras cumplir las obligaciones urbanísticas y la petición de licencia de obras.

En teoría, dado que una ley nacional o provincial, no puede regular en detalle todos los aspectos del uso suelo y edificación - entre ellos la protección del patrimonio arquitectónico y urbano -, debe encargar esta labor a diversos Planes Especiales de Protección cuando se refieren al patrimonio cultural inmueble. Estos planes no se reducen a simples Códigos de Edificación u Ordenanzas sectorizadas, sino a normas que especifiquen como gestionar e intervenir técnicamente dichos bienes.

En el caso de ciudades que además posean dentro de su ejido bienes reconocidos por la UNESCO como Patrimonio de la Humanidad - como Córdoba, Alta Gracia y Jesús María -, deben garantizar según el Art.5, inc.d, de la Convención de Patrimonio Mundial la adopción de "medidas jurídicas (...) para identificar, proteger, conservar, revalorizar y rehabilitar el patrimonio".

Este deber es un compromiso de los Estados Partes que han solicitado tal reconocimiento de sus bienes en el marco de los principios de la citada Convención, y que como en el caso de la Republica Argentina, han ratificado su adhesión a la misma mediante Ley Nacional № 21835/78. Como se ha indicando antes, el cumplimiento de concreto de este deber es delegado a la administración municipal, siendo las 
ordenanzas para la protección de bienes culturales el instrumento jurídico base para cumplir con la obligación citada.

Cuando hablamos de un bien arquitectónico, nos referimos a:

un bien cultural que detente un interés público por sus valores culturales antropológicos - sean éstos históricos, artísticos, sociales, arquitectónicos, urbanísticos, paisajísticos, etnológicos, científicos, técnicos, arqueológicos, en cuanto estén relacionados con la cultura local -, y que merezcan protección y defensa especial, de manera que puedan ser disfrutados y transmitidos en las mejores condiciones a generaciones futuras. (1)

Estos bienes arquitectónicos nunca están aislados, están insertos en un ambiente natural o urbano. Las agrupaciones homogéneas de estos bienes, construcciones urbanas o rurales, suelen identificarse como Conjuntos, Sitios y Zonas cuando sobresalen por su interés cultural, "con coherencia suficiente para constituir unidades susceptibles de clara delimitación". (2)

Se conoce que existen innumerables definiciones de este tipo, pero a los efectos de su protección legal interesa establecer que lo que se reconoce como patrimonio cultural, sea tangible o intangible, posee valores especiales desde algún aspecto de la cultura.

\section{Las carencias en las ordenanzas argentinas vigentes sobre bienes culturales arquitectónicos.}

Un estudio de las ordenanzas vigentes -especialmente en la provincia de Córdoba -, y su comparación con otras normas similares evidencian ciertas carencias en su formulación, entre las que pueden mencionar:

1.1 Primera consideración: ¿Qué se protege? ¿Dónde se protege? La identificación del bien.

La tutela del patrimonio inmueble no se circunscribe a los bienes que en si mismos están dotados de valor cultural, sino que se extiende sobre otros bienes que aún no poseyendo esa naturaleza, se encuentra con aquellos en una particular relación, que hace necesaria una intervención pública. 
Esta área en la cual se mantienen ciertas relaciones de perspectivas con el espacio inmediato de los bienes culturales, se lo denomina en el lenguaje jurídico "entorno", espacio que influye directamente en su capacidad de representar un valor cultural. Los entornos han sido espacios desatendidos por la falta de normativas claras que dispusieran el régimen de actuación en ellos, lo que produjo una drástica ruptura de escala urbana.

El problema fundamental es la imprecisión física de estos espacios. La expresión referente al entorno como "zona de respeto" es fruto de una práctica administrativa que pretende aplicar al entorno el mismo tratamiento normativo que a los monumentos, pero casi nunca está legitimada por algún texto legal. El entorno no suele estar comprendido en la declaratoria ni en las previsiones del Plan Urbano.

Lo primero que se debería esclarecer es el concepto de entorno y establecer el estatuto jurídico de los elementos integrantes del mismo, exigiendo en la declaración de los bienes la descripción completa del mismo más la delimitación del entorno afectado, comprendiendo también el subsuelo.

El volumen, la tipología, la morfología y el cromatismo de las intervenciones en los entornos no pueden alterar el carácter arquitectónico y paisajístico del área ni perturbar la visualización del bien.

En el entorno cultural otra cuestión jurídica clave es conocer con precisión si las consecuencias de orden jurídico afectan por igual al bien declarado y a su entorno y son el mismo espacio, con idéntico estatuto jurídico para ambos; ó son dos espacios, bien y entorno, con contenidos y efectos diferentes.

Puede, por ejemplo, proponerse que el bien cultural arquitectónico identificado detente las máximas obligaciones y derechos de la norma urbana; que su entorno sea la franja o espacio anular que lo circunda con menos cargas y beneficios, pero con un estatuto cautelar distinto de los que quedan fuera de él; y que al conjunto superficial de ambos se los denomine Zona, redactándose el planeamiento para la Zona completa de ambos tipos de espacios: Area + entorno. 


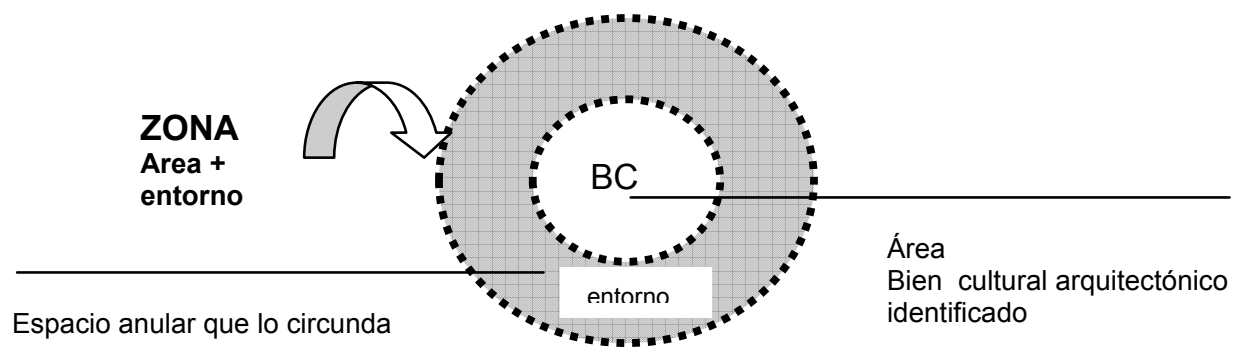

El bien cultural y su entorno. Esquema de elaboración propia

Los inmuebles, objetos unitarios con diferentes categorías, pueden ubicarse en múltiples posiciones diferentes: aisladamente, en el entorno de un Bien cultural arquitectónico identificado; dentro o en el entorno de un espacio cultural. En cada caso tendrían estatutos, deberes y derechos diferentes, incluso según para que tipo de obras.

Estos "espacios culturales" están caracterizados por la existencia de una pluralidad de elementos que, jurídicamente, son elementos con un estatuto muy diferente, aunque exista hoy base teórica suficiente para entender que hay en el medio ambiente un interés público unitario.

Si se parte de una existencia jurídica del "espacio cultural", será preciso diferenciarlo de otros espacios y definir sus componentes. La legislación deberá definir de acuerdo a qué parámetros se debe trazar el límite entre los espacios culturales, preservados desde la legislación cultural y/o urbana, y otras áreas para las cuales prevalecerá la disciplina urbanística clásica. Porque cuando no exista una declaración formal, la protección no existe y la ordenanza de edificación local se aplicará sobre ellos sin las poderosas cautelas suplementarias de una Ley u Ordenanza de Bienes Culturales.

Los Planes Urbanos Especiales que se encargan de esta labor y deben responder, como mínimo, a las siguientes exigencias:

a. Establecer el orden prioritario de los usos públicos de los edificios y espacios aptos para ellos;

b. Contemplar las posibles áreas de rehabilitación integrada del conjunto;

c. Contener los criterios relativos a la conservación de fachadas y cubiertas; 
d. Prohibir de alineaciones nuevas, alteraciones de edificabilidad, parcelaciones y agregaciones, conservando la forma estructura urbana y arquitectónica;

e. Catalogar según la legislación urbanística, los elementos unitarios que conforman el conjunto: inmuebles, espacios libres exteriores e interiores, estructuras significativas, componentes naturales, definiendo tipos de intervención posible, estableciendo una "protección integral" a los singulares y al resto un "nivel adecuado de protección" (3): Nivel I: protección integral; Nivel II: protección estructural; Nivel III: protección ambiental; Nivel IV: sin interés para su protección;

f. Regular la publicidad, cables, antenas, conducciones aparentes, etc.;

g. Coordinar la tutela del conjunto con otras actividades públicas;

h. Expropiar por causa de interés social los inmuebles que den lugar a riesgo de los bienes declarados.

i. Impedir el derribo por declaración de ruina de los inmuebles situados en el entorno de los BC.

En síntesis, cuando su objetivo específico es la protección del Patrimonio arquitectónico-urbano, la norma urbana deberá establecer parámetros de intervención para que las nuevas construcciones se adapten, en lo básico, al ambiente en que estuvieran situadas.

1.2 Segunda consideración: ¿quién protege al bien inmueble: el municipio, la provincia, la nación? ¿Mediante que organismos lo hace: cultura-urbanismo? La Autoridad de Aplicación.

La Constitución Nacional y la Provincial generalizan la obligación protectora del Patrimonio Cultural -aumentada en este caso por la responsabilidad internacional de la tutela-, a todos los poderes públicos, que finalmente recae como competencia de la Autoridad de Aplicación de las leyes y ordenanzas de Protección de Bienes Culturales. Competencia que se aplica en el suelo urbano (público o privado) que es de incumbencia municipal; y el Municipio deberá, a través de un instrumento urbanístico especial, delimitar el contenido del derecho de propiedad de acuerdo a su función social. Para que esta función se pueda determinar es necesario contar con Leyes de Suelo y de Bienes Culturales, y sus autoridades de aplicación de acuerdo al nivel administrativo de gobierno. Del mismo modo, la organización de la protección del 
patrimonio cultural se corresponde con los niveles administrativos y sus respectivos alcances territoriales, incluso en la identificación del valor cultural que un bien posee: barrial, municipal, provincial, nacional, internacional.

La inexistencia de una Ley de Suelo y de la Ordenación del Territorio a través del Planeamiento Urbano en el caso argentino dificulta la organización eficaz de la protección, aunque en un régimen federal de gobierno, las provincias tienen la capacidad de aprobar leyes en materia de ordenación del territorio. Además la legislación existente presenta problemas de concurrencia de administraciones al no definir las competencias de las mismas. El nivel administrativo que finalmente estudia, desarrolla e implementa tanto el Plan General como los Planes Especiales, es el Municipio, autónomo y con atribuciones en la materia, según la Constitución Provincial. La necesidad de este tipo de legislación es evidente, ya que su carencia origina severos problemas urbanos y pérdidas irreversibles en el patrimonio inmueble.

1.3 Tercera consideración: ¿cómo asegurar la protección del bien inmueble? Los incentivos a la protección.

La nueva legislación sobre bienes culturales plantea la problemática de la gestión, intervención y mantenimiento de los monumentos, sean privados ó públicos. Se incentiva la educación para el conocimiento de los bienes culturales, además de proponer incentivos fiscales, tributarios y no tributarios, para asegurar su mantenimiento y sustentabilidad.

Entre estas medidas, la rehabilitación es una técnica de fomento dirigida especialmente a viviendas con algún valor patrimonial, que utiliza medios similares a la promoción de Viviendas de Interés Social, como préstamos cualificados, subsidios de los tipos de interés, subvenciones personales a adquirentes y usuarios, y/o exenciones y bonificaciones tributarias.

Entre los requisitos a establecer para acceder a este tipo de promoción cabe mencionar, por ejemplo, que los edificios beneficiados tendrán una antigüedad superior a 10 años, excluyéndose la posibilidad de demolición o vaciado interior; que el destino de la obra será vivienda permanente ó, en su defecto un $70 \%$ de la 
superficie total estará destinado a tal uso; y que se otorgarán a partir de cierto monto de obra, estimado en la relación a los costos de mercado y al tipo de intervención.

Los beneficios posibles podrán ser traducidos en préstamos cualificados (ayuda económica personal tipo Vivienda de Interés Social), Subsidios de los tipos de interés, Subvenciones personales a adquirentes y usuarios, y/o exenciones y bonificaciones tributarias.

1.4 Cuarta consideración: ¿Cuánto y dónde? ¿De quién es lo que se protege? La propiedad del bien cultural.

El ordenamiento jurídico es un todo unitario, y al igual que somete los bienes cualquiera sea su régimen jurídico y titularidad a los fines de la protección del Patrimonio Cultural, reconoce una propiedad privada, de la que nadie podrá ser despojado. Sin embargo cuando la propiedad posee valores culturales que se reconocen objetivamente en esos bienes -arte, historia, ambiente, etc. -, éstos desbordan por su importancia el ámbito privado y pertenecen a la colectividad.

La tutela urbana del patrimonio inmueble, privado en su mayoría, deberá intentar encontrar una posición intermedia entre el planeamiento urbano (textos normativos que permiten intervenir en el territorio y en la ciudad desde los poderes públicos) y una libertad total de uso del suelo (el derecho constitucional a la propiedad privada).

Cuando lo establezca la Reglamentación sus propietarios deberán solicitar licencia de obra para efectuar actuaciones en ellos, como por ejemplo: Intervención y mantenimiento en bienes declarados; Ruinas de edificios; Expropiaciones; Restauraciones; Publicidad; Reconstrucciones, etc.

\section{Propuesta de una estructura tipo para la elaboración de ordenanzas para la protección de bienes culturales inmuebles. (4)}

De acuerdo a las consideraciones antes citadas, se propone que en la elaboración de ordenanzas relacionadas con el reconocimiento y protección del patrimonio 
arquitectónico en el nivel municipal se deben tener en cuenta una serie de ítems, que se resumen en el siguiente esquema:

\begin{tabular}{|c|c|c|}
\hline & Tema & $\begin{array}{l}\text { Aspecto del tema a tratar en la ordenanza } \\
\text { (en relación al patrimonio inmueble) }\end{array}$ \\
\hline \multicolumn{3}{|c|}{ LA ORDENANZA } \\
\hline 1 & Formulación del Titulo & $\begin{array}{l}\text { Especificar que tiene por misión proteger bienes } \\
\text { culturales }\end{array}$ \\
\hline 2 & $\begin{array}{l}\text { Exposición de propósitos o } \\
\text { fundamentación }\end{array}$ & $\begin{array}{l}\text { Vistos y Considerandos con los objetivos y motivos de la } \\
\text { ordenanza, y el marco jurídico nacional y provincial. }\end{array}$ \\
\hline 3 & $\begin{array}{l}\text { Fin de la ordenanza como } \\
\text { instrumento jurídico }\end{array}$ & $\begin{array}{l}\text { Explicitar su fin como instrumento jurídico para la } \\
\text { protección del patrimonio cultural y su uso como } \\
\text { instrumento cultural. } \\
\text { Determinar alcance municipal }\end{array}$ \\
\hline 4 & $\begin{array}{l}\text { Reglamento de la } \\
\text { Ordenanza }\end{array}$ & $\begin{array}{l}\text { Indicar su necesidad para cumplir y completar los fines en } \\
\text { el articulado, y plazo para su elaboración. }\end{array}$ \\
\hline \multicolumn{3}{|c|}{ AUTORIDAD ¿Quién? } \\
\hline 1 & Autoridad de Aplicación & $\begin{array}{l}\text { Determinar composición, procedimientos y dependencia } \\
\text { de Organismo Municipal de Aplicación, y sus organismos } \\
\text { asesores. } \\
\text { Especificar en Reglamento funciones e incumbencias }\end{array}$ \\
\hline \multicolumn{3}{|c|}{ EI PATRIMONIO CULTURAL ¿Qué y cuanto? } \\
\hline 1 & Fin del Patrimonio Cultural & $\begin{array}{l}\text { Especificar si existen principios constitucionales y } \\
\text { políticas culturales. } \\
\text { Establecer como fin del patrimonio cultural municipal su } \\
\text { función social y cultural }\end{array}$ \\
\hline 2 & $\begin{array}{l}\text { Definiciones de términos a } \\
\text { los fines de la Ordenanza }\end{array}$ & $\begin{array}{l}\text { Patrimonio Cultural / Bienes Culturales /Otros. } \\
\text { Indicar que el interés publico que poseen en función de } \\
\text { sus valores especiales desde algún aspecto de la cultura. } \\
\text { Ampliar criterios de valoración en el Reglamento. }\end{array}$ \\
\hline 3 & Categorías de los bienes & $\begin{array}{l}\text { Listado: enumera bienes } \\
\text { Categorías: establece características y valores para } \\
\text { agrupar los bienes: bienes culturales, conjuntos, lugares, }\end{array}$ \\
\hline
\end{tabular}




\begin{tabular}{|c|c|c|}
\hline & & actividades culturales, bienes naturales, trazado urbano. \\
\hline 4 & $\begin{array}{l}\text { Procedimiento para la } \\
\text { Declaración. } \\
\text { Derecho Administrativo }\end{array}$ & $\begin{array}{l}\text { Establecer secuencia: identificación, inventario, } \\
\text { declaración. } \\
\text { Formalización de la Declaración por ordenanza del HCD } \\
\text { o por decreto del PE. } \\
\text { Incorporación de bienes declarados con anterioridad, } \\
\text { especificar en Reglamento }\end{array}$ \\
\hline 5 & $\begin{array}{l}\text { Registro de bienes } \\
\text { Inventarios }\end{array}$ & $\begin{array}{l}\text { Catalogación e Inventario, manual y/o digital. } \\
\text { Instituciones consultivas para su elaboración. } \\
\text { Indicar datos básicos de las fichas en Reglamento. }\end{array}$ \\
\hline & JLARIDAD DE LOS BIENES & ¿de quién y cómo? \\
\hline 1 & $\begin{array}{l}\text { Titularidad de los bienes } \\
\text { Código Civil }\end{array}$ & $\begin{array}{l}\text { Indicar posibilidades de dominio: } \\
\text { - Del Estado (Nacional, Provincial o Municipal) en función } \\
\text { de la utilidad o interés público. Casos de expropiación. } \\
\text { - Privados. Notificación y convenios con el Municipio. }\end{array}$ \\
\hline 2 & $\begin{array}{l}\text { Deberes y derechos del } \\
\text { Propietario Privado }\end{array}$ & $\begin{array}{l}\text { Elaboración de Convenio con el Municipio: indicar } \\
\text { derechos y obligaciones mínimas: mantenimiento, } \\
\text { régimen de visitas, solicitud de ayuda para su } \\
\text { conservación, etc. } \\
\text { Establecer la obligación de solicitar autorización para } \\
\text { cualquier intervención en bienes declarados. }\end{array}$ \\
\hline \multicolumn{3}{|c|}{ LA ADMINISTRACION DE LOS BIENES ¿Quién? } \\
\hline 1 & $\begin{array}{ll}\text { Gestión } & \text { de la } \\
\text { Administración Municipal }\end{array}$ & $\begin{array}{l}\text { Indicar gestión y proyectos para asegurar la conservación } \\
\text { de los bienes culturales } \\
\text { Establecer la necesidad de Convenios con otros niveles } \\
\text { de administración para cumplir con los objetivos de la } \\
\text { ordenanza y su reglamento. }\end{array}$ \\
\hline 2 & $\begin{array}{l}\text { Concurrencia } \\
\text { administraciones }\end{array}$ & $\begin{array}{l}\text { Señalar concurrencia de poderes según administración } \\
\text { federal. Especificar prohibición para el traslado de los } \\
\text { bienes culturales municipales. } \\
\text { Determinar los alcances de la responsabilidad del } \\
\text { Municipio }\end{array}$ \\
\hline 3 & Campañas Educativas & Fijar la necesidad de difundir el valor cultural del \\
\hline
\end{tabular}




\begin{tabular}{|c|c|c|}
\hline & & $\begin{array}{l}\text { Patrimonio. } \\
\text { Proponer su uso como instrumento de educación. } \\
\text { Crear instituciones vinculadas al Patrimonio: Museos, } \\
\text { Parques, Archivos y Bibliotecas. }\end{array}$ \\
\hline \multicolumn{3}{|c|}{ DISPOSICIONES ESPECIALES ¿Dónde? } \\
\hline 1 & Ordenación del Territorio & $\begin{array}{l}\text { Establecer relación con Planes de desarrollo urbano. } \\
\text { Establecer relación con Código de Edificación: superficie } \\
\text { y volumen edificable, altura de la edificación, } \\
\text { marquesinas, aleros, salientes en pisos altos, línea de } \\
\text { edificación, anchos mínimos, tipos y ensanches de } \\
\text { veredas, veredas arboladas, iluminación, y dimensiones } \\
\text { mínimas de locales, etc. }\end{array}$ \\
\hline 2 & \begin{tabular}{|lll} 
Dictado de Normas \\
Especiales
\end{tabular} & $\begin{array}{l}\text { Establecer la necesidad de la redacción de Reglamentos } \\
\text { y Normas para completar disposiciones de la Ordenanza. } \\
\text { Delimitar el trazado original del asentamiento como Área } \\
\text { Especial y Área Arqueológica Urbana. Indicar la adhesión } \\
\text { a Acuerdos Internacionales sobre el tema. }\end{array}$ \\
\hline \multicolumn{3}{|c|}{ SANCIONES } \\
\hline 1 & $\begin{array}{l}\text { Sanciones } \\
\text { Código Penal } \\
\text { Ordenanza Tributaria y de } \\
\text { Faltas }\end{array}$ & $\begin{array}{l}\text { Procedimiento de Inspecciones. Exenciones. Especificar } \\
\text { en Reglamento. } \\
\text { Especificar motivo de las sanciones: Destrucción del valor } \\
\text { del bien cultural, agresión a su soporte físico, } \\
\text { intencionalmente o no, negligencia administrativa, etc. }\end{array}$ \\
\hline \multicolumn{3}{|c|}{ RECURSOS ¿cómo? } \\
\hline 1 & $\begin{array}{|lll|}\text { Fondos } & \text { previstos } & \mathrm{y} \\
\text { Recursos } & & \\
\text { Ordenanza } & \text { Tributaria } & \\
\end{array}$ & Crear Fondos especiales. Especificar en Reglamento \\
\hline 2 & Patronatos y Fundaciones & ONG. Especificar en Reglamento \\
\hline 3 & $\begin{array}{l}\text { Exenciones Fiscales } \\
\text { Código Fiscal } \\
\text { Ordenanza Tributaria }\end{array}$ & $\begin{array}{l}\text { Determinar medios: eximir pago de tasas y servicios, } \\
\text { donaciones, preferencia de adquisición oficial. Especificar } \\
\text { en Reglamento }\end{array}$ \\
\hline
\end{tabular}


La ordenanza de protección de bienes culturales se ocupa del reconocimiento de los bienes, pero para que sea eficaz, es necesario su reglamentación y su vinculación a normativas urbanas especiales.

\section{Conclusiones}

Tras el análisis de nuestra legislación relacionada al reconocimiento y protección de bienes culturales inmuebles que poseen reconocimiento internacional por su valor excepcional, en comparación con la existente en otros países, se ha constatado que los mayores déficit de la misma se refieren a:

a. La planificación territorial y urbana vinculada al patrimonio inmueble: los Planes Especiales de Protección.

b. La protección del entorno del patrimonio inmueble

c. Un enfoque multidisciplinario en la tutela de bienes culturales: disciplinas vinculadas (paisaje, arqueología, etnografía, documentación, etc.).

d. Conocimiento preciso y definido de la esencia del patrimonio inmueble a proteger: tipificación y categorización.

e. Los incentivos económicos y fiscales en la protección del patrimonio inmueble.

La protección de bienes aislados - noción cultural del patrimonio -, con límites incompatibles con el interés de conservación integral, no condice con el mandato constitucional y el deber internacional de enriquecer el patrimonio colectivo. Esta segmentación de un ambiente cuyos valores superan ampliamente casos puntuales noción urbana del patrimonio-, puede deberse a la reducida importancia que el patrimonio doméstico tenia al momento de redactar estas normas. Los Planes Especiales de Protección aparecen en las recomendaciones internacionales como los instrumentos de la planificación urbana que, atendiendo al bien singular y a su entorno, pueden llegar a vincular la noción cultural y urbana del patrimonio inmueble, asegurando su tutela integral, es decir especificando quién, de qué, como, cuánto, dónde y cuando debe preocuparse y ocuparse de un bien cultural arquitectónico.

\section{Notas}

(1) Proyecto de Ordenanza de Bienes Naturales y Culturales del Municipio de Capilla del Monte, Córdoba. 
(2) Ley 1/1993, CCAA de Andalucía, España: Patrimonio Histórico de la Comunidad Andaluza.

(3) Ley de Patrimonio Histórico Español, 16/1985

(4) La estructura que se presenta se basa en proyectos de ordenanza y reglamentos (sancionados o en comisión), como las Ordenanzas de Bienes Culturales de las Ciudades de Alta Gracia, Río Cuarto, Tanti, Villa de Soto y Capilla del Monte (Provincia de Córdoba, Argentina), así como en el Manual de Procedimiento para las Actuaciones en el Área de Primer Orden de Alta Gracia, en cuya elaboración se ha asesorado y/o participado.

\section{Bibliografía}

ALONSO IBAÑEZ, María del Rosario. El patrimonio histórico: destino público y valor cultural. Madrid: Editorial Civitas, 1992. 454 p..

BALLART, Josep. El patrimonio histórico y arqueológico: valor y uso. Barcelona: Ariel, 1977. 268 p.

DE GRACIA, Francisco. Construir en lo construido: la arquitectura como modificación. Madrid: Nerea, 1996. 323 p.

GONZALEZ-VARAS, Ignacio. Conservación de bienes culturales. teoría, historia, principios y normas. Manuales Arte Cátedra. Madrid: Ediciones Cátedra, 1999. 628 p.

MACARRÓN MIGUEL, Ana María; GONZÁLEZ MOZO, Ana. La conservación y la restauración en el siglo XX. Madrid: Tecnos, 1998. 216 p.

PRATS, Llorenço. Antropología y patrimonio. Barcelona: Ariel Antropología, 1997. 171 p.

QUEROL, María de los Angeles; MARTÍNEZ DÍAZ, Belén. La gestión del patrimonio arqueológico en España. Madrid: Alianza Editorial, 1996. 438 p.

\section{Artículos y/o Publicaciones:}

ALVAREZ ALVAREZ, José Luis. El patrimonio cultural: de donde venimos, donde estamos a donde vamos. Revista Patrimonio Cultural y Derecho, Madrid: Boletin Oficial del Estado y coeditores, n. 1, p. 15, 1997.

INSTITUTO COLOMBIANO DE CULTURA. Normas mínimas para la conservación de los bienes culturales. Bogotá: [1975?].

MEDINA, María Rebeca. Protección legal del patrimonio edificado. Informe Final Beca de Perfeccionamiento CONICOR, Córdoba. (Manuscrito no publicado, 1999). 
MEDINA, María Rebeca. Protección legal del patrimonio edificado: propuesta de proyecto para una Ley de Bienes Culturales de la Provincia de Córdoba. Informe Final Beca de Perfeccionamiento CONICOR, Córdoba. (Manuscrito no publicado, 2000).

* Arquitecta - Facultad de Arquitectura, Urbanismo y Diseño (FAUDI) - Universidad Nacional de Córdoba, Argentina. Master Internacional en Rehabilitación del Patrimonio Edificado - CICOP, Tenerife, Canarias, España. Docente Investigador FAUDI, Cátedra de Historia de la Arquitectura I y III e Historia Crítica; docente invitado Master Internacional de Turismo, Universidad de las Palmas de Gran Canaria, España; arquitecta de la Área de Conservación Edilicia Museo Nacional Estancia Jesuítica de Alta Gracia. 